Universidade Tecnológica Federal do Paraná - UTFPR

Campus Ponta Grossa - Paraná - Brasil

ISSN: 1981-3686/v. 04, n. 01: p. 58-71, 2010

D.O.I.: $10.3895 / \mathrm{S} 1981-36862010000100007$
Revista Brasileira deTecnologia

Agroindustrial

\title{
UTILIZAÇÃO TECNOLÓGICA DE SEMENTE DE ABÓBORA NA ELABORAÇÃO DE BISCOITOS FONTES DE FIBRA ALIMENTAR E SEM ADIÇÃO DE AÇÚCAR
}

\section{TECHNOLOGICAL USE OF PUMPKIN SEED IN DEVELOPMENT OF COOKIES WITHOUT SUGAR AS DIETARY FIBER SOURCE}

\author{
Juliana Bergonsi da Silva ${ }^{1}$; Cláudia Schlabitz ${ }^{2}$; Claucia Fernanda Volken de Souza ${ }^{3}$ \\ ${ }^{1}$ Centro Universitário - UNIVATES - Lajeado - Brasil julianabergonsi@ gmail.com \\ ${ }^{2}$ Centro Universitário - UNIVATES - Lajeado - Brasil claudinhakimica@ yahoo.com.br \\ ${ }^{3}$ Centro Universitário - UNIVATES - Lajeado - Brasil clauciavolken@ bol.com.br
}

\section{Resumo}

A busca por alimentos isentos de açúcar está crescendo cada vez mais, tanto por pessoas portadoras de diabetes melito, quanto por consumidores que buscam produtos com teor reduzido de açúcar. Além disso, atualmente, a fim de minimizar a quantidade de resíduos agroindustriais tornou-se importante a utilização desses na elaboração de alimentos alternativos ricos em fibras, sais minerais e ácidos graxos, como no caso da semente de abóbora. Assim, este trabalho teve como objetivo elaborar biscoitos sem adição de açúcar, utilizando edulcorantes intensivos, polidextrose e farinha de semente de abóbora, que apresentem qualidade sensorial e nutricional. Os edulcorantes utilizados foram: sucralose, acessulfame-K e esteviosídeo, isolados e em combinação. As farinhas de semente de abóbora e trigo foram utilizadas em proporção de 1:1. Com a exclusão total de açúcar foi necessária a utilização de polidextrose, sendo esta uma fibra que possibilita a correção de corpo e efeito prebiótico ao produto. Todas as amostras foram submetidas às análises químicas e sensoriais. Os resultados da composição química destacaram teores significativos de fibras, lipídios e proteínas em todas as formulações. Na análise sensorial, os resultados mostraram que a utilização da sucralose superou a aceitação dentre as amostras analisadas, até mesmo em relação à formulação padrão, que continha açúcar. Os resultados obtidos demonstraram a viabilidade da adição de semente de abóbora em forma de farinha, a fim de obter biscoitos enriquecidos em fibra alimentar, com qualidade organoléptica, e ainda da utilização de edulcorantes intensivos e polidextrose na elaboração de biscoitos sem adição de açúcar.

Palavras-chaves: semente; abóbora; biscoito; sacarose.

\section{Introdução}

A indústria alimentícia vem utilizando fontes alternativas de vegetais com o intuito de fornecer produtos mais saudáveis e ricos em fibras. Em consequência, sementes de várias espécies se tornaram recursos alternativos para a alimentação humana, mostrando-se excelentes fontes naturais de fibras alimentares (AMBROSIO, 2006). A semente de abóbora é um subproduto, que além de ser rica em fibras, é fonte natural de proteínas e fitoesteróis (CERQUEIRA et al., 2008a; 
MOHAMED et al., 2009). Apesar da sua importância nutricional essas sementes são consideradas resíduos agroindustriais, sendo desperdiçadas em grande quantidade pelas indústrias processadoras de vegetais.

Além de produtos nutritivos, a busca da população por um produto sugar free também é ascendente, tanto por pessoas que possuem alguma intolerância ao açúcar, portadoras de diabetes melito ou com excesso de peso, quanto por consumidores que apenas buscam alimentos com menor ou isento de concentração de açúcar ou calorias (CARDOSO; BOLINI, 2007). Segundo a Portaria n 29 (BRASIL, 1998), para os alimentos possuírem a alegação de diet necessitam de uma redução severa em um determinado nutriente. Dessa forma, um alimento para ser considerado diet em açúcar e especialmente formulado para atender às necessidades de indivíduos com distúrbios no metabolismo de açúcar deve ser isento ou possuir no máximo $0,5 \%$ de açúcares em sua composição em relação ao produto convencional.

Com a exclusão total do açúcar na preparação de um determindo produto torna-se necessária a adição de edulcorantes para conferir sabor doce. Os edulcorantes de alta intensidade, tais como sucralose, acessulfame de potássio $(\mathrm{K})$ e extrato de folhas de estévia são permitidos pela legislação brasileira e podem ser utilizados por gestantes, por portadores de diabetes melito ou mesmo no controle de peso, pois são nulos em sacarose e valor energético (BRASIL, 1995; TORNOLI et al., 2007; ESTELLER, 2004; MACEDO, 2005). Esses edulcorantes possuem Ingestão Diária Aceitável (IDA), estabelecida pelo Joint Expert Committee on Food Aditives (JECFA), e o limite tecnológico em g/100 g de produto estabelecido pela legislação brasileira na RDC $\mathrm{n}^{\circ} 18$ (BRASIL, 2008). A Food and Drug Administration (FDA) aprova o uso da sucralose e do acessulfame-K como edulcorantes intensivos, no entanto o extrato de folhas de estévia tem aprovação apenas como suplemento dietético e não como edulcorante (TORLONI et al., 2007). Tanto a sucralose, quanto o extrato de folhas de estévia e o acessulfame-K apresentam estabilidade em solução aquosa, altas temperaturas e amplas faixas de $\mathrm{pH}$, podendo desta forma, serem submetidos a temperaturas elevadas (ESTELLER, 2004; MACEDO, 2005; FERNANDES et al., 2009).

A polidextrose é um polímero de glicose, em pó, com coloração creme, que não confere sabor e odor aos alimentos. O seu uso em diferentes formulações deve ser associado com outros agentes de corpo ou edulcorantes que confiram sabor doce. Esse poliol propicia a manutenção do teor de sólidos, da textura e atribui características semelhantes às da sacarose, por possuir alta higroscopicidade (GOMES et al., 2007). Além desses atributos, ela é considerada um ingrediente funcional, pois é composta por $90 \%$ de fibras solúveis, estimulando o crescimento de lactobacilos e bifidobactérias e a fermentação contínua ao longo do cólon, promovendo desta forma efeito prebiótico ao alimento (JIE et al., 2000). Esta fermentação resulta na redução do pH fecal e na 
produção de ácidos graxos de cadeia curta, destacando-se o butirato, que pode reduzir os riscos de câncer (PAUCAR-MENACHO et al., 2008).

Portanto, este trabalho teve como objetivo elaborar biscoitos que apresentem qualidade sensorial e nutricional com farinha de semente de abóbora e sem adição de açúcar, utilizando diferentes edulcorantes intensivos e polidextrose.

\section{Material e Métodos}

\section{Material}

\section{Sementes de abóbora}

As sementes de abóbora (Curcubita maxima) foram doadas por duas unidades da fruteira Degasperi e Degasperi Atacadista (Lajeado e Estrela, RS). Primeiramente, as sementes foram lavadas em água corrente para a retirada de tecido vegetal e a seguir submetidas a tratamento térmico por $10 \mathrm{~min}$ em água fervente e após assadas em forno a $230{ }^{\circ} \mathrm{C}$ por aproximadamente 45 min, seguindo as recomendações de DEL-VECHIO et al. (2005). Após, foram armazenadas em freezer a $-18{ }^{\circ} \mathrm{C}$, sendo trituradas em liquidificador doméstico no momento do preparo das amostras de biscoito.

\section{Edulcorantes}

Para elaboração dos biscoitos foram utilizados os edulcorantes intensivos sucralose (Splenda®, Tale \& Lale), extrato de folhas de estévia, genericamente chamado de esteviosídeo (Steviapharma do Brasil) e acessulfame-K (Sweetmix®). Como agente de corpo foi utilizada a polidextrose (Litesse ${ }^{\circledR}$, Danisco). Os demais ingredientes foram adquiridos no comércio local.

\section{Métodos}

\section{Elaboração dos biscoitos}

Os biscoitos foram produzidos no Laboratório de Técnica Dietética da UNIVATES, sendo elaboradas sete diferentes formulações (Tabela 1), seis com os edulcorantes sucralose, esteviosídeo ou acessulfame-K e uma com sacarose (formulação padrão). Foram mantidas fixas as quantidades de farinha de semente de abóbora (FSA) e de farinha de trigo (FT), em proporção de 1:1, essência de baunilha, polidextrose, margarina, sal, fermento químico e ovo.

Os ingredientes foram pesados em balança eletrônica semi-analítica marca Marte, com exceção dos edulcorantes que foram pesados em balança analítica Bioprecisa.

Para a elaboração dos biscoitos, primeiramente foram misturados os ingredientes secos: FT, FSA, sal, polidextrose ou sacarose, fermento químico e os edulcorantes. Em outro recipiente foram 
adicionados os demais ingredientes: gema, essência de baunilha, margarina e, por último, as claras em neve, previamente, batidas em batedeira da marca Britânia, em velocidade $n^{\circ} 3$ por 2 min. Após, todos os ingredientes foram misturados, sendo que o tempo de mistura para a obtenção de uma massa homogênea foi de, aproximadamente, $10 \mathrm{~min}$. A massa dos biscoitos foi amassada manualmente, dividida em pequenas porções, para assim ser estendida com rolo de madeira. Em seguida, os biscoitos foram moldados com o uso de uma forma circular para padronização do tamanho. Todas as amostras foram assadas em forno de convecção da marca Ottima, durante 15 min a $160{ }^{\circ} \mathrm{C}$. Cada formulação rendeu 85 unidades de biscoitos.

Tabela 1- Formulações dos biscoitos elaborados com FSA, diferentes edulcorantes e polidextrose ou sacarose

\begin{tabular}{lccccccc}
\hline \multicolumn{1}{c}{ Ingredientes (g) } & \multicolumn{7}{c}{ Formulação } \\
\cline { 2 - 7 } & F1 & F2 & F3 & F4 & F5 & F6 & F7 \\
\hline Essência de baunilha & 9,27 & 9,27 & 9,27 & 9,27 & 9,27 & 9,27 & 9,27 \\
FT & 214,50 & 214,50 & 214,50 & 214,50 & 214,50 & 214,50 & 214,50 \\
FSA & 214,50 & 214,50 & 214,50 & 214,50 & 214,50 & 214,50 & 214,50 \\
Polidextrose & 168,00 & 168,00 & 168,00 & 168,00 & 168,00 & 168,00 & 0,00 \\
Sacarose & 0,00 & 0,00 & 0,00 & 0,00 & 0,00 & 0,00 & 168,00 \\
Margarina & 108,00 & 108,00 & 108,00 & 108,00 & 108,00 & 108,00 & 108,00 \\
Sal & 1,48 & 1,48 & 1,48 & 1,48 & 1,48 & 1,48 & 1,48 \\
Fermento químico & 13,20 & 13,20 & 13,20 & 13,20 & 13,20 & 13,20 & 13,20 \\
Ovo & 168,00 & 168,00 & 168,00 & 168,00 & 168,00 & 168,00 & 168,00 \\
Sucralose & 0,1345 & 0,0000 & 0,0000 & 0,2690 & 0,1345 & 0,0000 & 0,0000 \\
Esteviosídeo & 0,0000 & 0,4030 & 0,0000 & 0,0000 & 0,2015 & 0,2015 & 0,0000 \\
Acessulfame-K & 0,1475 & 0,0000 & 0,2950 & 0,0000 & 0,0000 & 0,1475 & 0,0000 \\
\hline
\end{tabular}

Análises físico-químicas dos biscoitos

A composição química das formulações dos biscoitos foi determinada através dos seguintes procedimentos: umidade em estufa a $105{ }^{\circ} \mathrm{C}$ até peso constante, cinzas por incineração a $550{ }^{\circ} \mathrm{C}$, lipídios pelo método de extração direta por solvente (Método de Soxleht) e proteína através da determinação do teor de nitrogênio total pelo Método de Kjeldahl e convertido em proteína bruta pelo fator 6,25, conforme metodologias do Instituto Adolfo Lutz (2005). A fibra alimentar foi determinada segundo Método 985.29 da AOAC (1995). O teor de carboidratos totais foi determinado pelo cálculo da diferença de 100 gramas de biscoito e a soma total dos valores encontrados para os componentes citados. As determinações da atividade de água foram realizadas utilizando um medidor eletrônico Aqualab Decagon (CX-2).Todas as análises foram realizadas em triplicata.

\section{Análises sensoriais dos biscoitos}

A análise sensorial dos biscoitos foi realizada no Laboratório de Análise Sensorial da UNIVATES por uma equipe formada por 83 provadores selecionados e não treinados. Cada julgador avaliou as amostras identificadas por códigos aleatórios de três dígitos em cabines 
individuais e com iluminação branca natural. Foram avaliados os seguintes atributos: aparência, sabor, dureza, textura e aceitação global do produto através do teste de escala estruturada de nove pontos.

\section{Análise estatística}

Para comparar os resultados físico-químicos e sensoriais das diferentes formulações de biscoitos foi realizada a Análise de Variância (ANOVA) dos dados e para a comparação de médias o teste de Tukey $(\mathrm{p} \leq 0,05)$, utilizando o software Statistica versão 7.0.

\section{Resultados e Discussão}

Análises físico-químicas dos biscoitos

A Tabela 2 apresenta os resultados das análises físico-químicas dos biscoitos sem adição de açúcar. As amostras estão denominadas por F1, F2, F3, F4, F5 e F6, representando as amostras com os edulcorantes: sucralose + acessulfame-K, esteviosídeo, acessulfame-K, sucralose, sucralose + esteviosídeo e esteviosídeo + acessulfame-K, respectivamente.

Tabela 2 - Resultados* das análises físico-químicas** dos biscoitos elaborados com FSA e diferentes edulcorantes

\begin{tabular}{ccccccc}
\hline Amostra*** & $\begin{array}{c}\text { Cinzas } \\
(\boldsymbol{\%})\end{array}$ & $\begin{array}{c}\text { Lipídios } \\
(\boldsymbol{\%})\end{array}$ & $\begin{array}{c}\text { Proteínas } \\
(\boldsymbol{\%})\end{array}$ & $\begin{array}{c}\text { Fibra Alimentar } \\
(\boldsymbol{\%})\end{array}$ & $\begin{array}{c}\text { Carboidratos } \\
(\boldsymbol{\%})\end{array}$ & $\begin{array}{c}\text { Atividade de } \\
\text { água }\end{array}$ \\
\hline F1 & $2,71 \pm 0,06^{\mathrm{a}}$ & $25,64 \pm 0,27^{\mathrm{a}}$ & $15,96 \pm 0,18^{\mathrm{b}}$ & $29,93 \pm 0,44^{\mathrm{a}}$ & $25,76 \pm 0,81^{\mathrm{ab}}$ & $0,651 \pm 0,00^{\mathrm{c}}$ \\
F2 & $2,75 \pm 0,07^{\mathrm{a}}$ & $25,73 \pm 0,16^{\mathrm{a}}$ & $15,88 \pm 0,16^{\mathrm{b}}$ & $30,07 \pm 0,44^{\mathrm{a}}$ & $25,58 \pm 0,39^{\mathrm{b}}$ & $0,645 \pm 0,00^{\mathrm{d}}$ \\
F3 & $2,71 \pm 0,05^{\mathrm{a}}$ & $25,69 \pm 0,13^{\mathrm{a}}$ & $15,67 \pm 0,65^{\mathrm{b}}$ & $29,95 \pm 0,31^{\mathrm{a}}$ & $25,98 \pm 0,51^{\mathrm{ab}}$ & $0,629 \pm 0,00^{\mathrm{e}}$ \\
F4 & $2,97 \pm 0,41^{\mathrm{a}}$ & $24,56 \pm 0,30^{\mathrm{b}}$ & $15,54 \pm 0,03^{\mathrm{b}}$ & $29,78 \pm 0,68^{\mathrm{a}}$ & $27,15 \pm 0,71^{\mathrm{a}}$ & $0,698 \pm 0,00^{\mathrm{b}}$ \\
F5 & $2,86 \pm 0,06^{\mathrm{a}}$ & $25,94 \pm 0,10^{\mathrm{a}}$ & $16,11 \pm 0,31^{\mathrm{b}}$ & $30,02 \pm 0,35^{\mathrm{a}}$ & $25,06 \pm 0,17^{\mathrm{bc}}$ & $0,655 \pm 0,00^{\mathrm{c}}$ \\
F6 & $2,61 \pm 0,05^{\mathrm{a}}$ & $24,83 \pm 0,07^{\mathrm{b}}$ & $18,56 \pm 0,16^{\mathrm{a}}$ & $30,08 \pm 0,43^{\mathrm{a}}$ & $23,92 \pm 0,16^{\mathrm{c}}$ & $0,716 \pm 0,00^{\mathrm{a}}$ \\
\hline
\end{tabular}

Resultados na mesma coluna com diferentes expoentes diferem significativamente $(p \leq 0,05)$, conforme resultado do teste de Tukey.]** Composição centesimal expressa em base seca. *** F1 - Sucralose + acessulfame-K; F2 Esteviosídeo; F3 - Acessulfame-K; F4 - Sucralose; F5 - Sucralose + esteviosídeo; F6 - Esteviosídeo + acessulfame-K.

Em relação à atividade de água (Aw) foram observadas diferenças significativas $(p \leq 0,05)$ entre a maioria das formulações. Com relação às amostras que continham os edulcorantes isolados, a amostra F3 apresentou menor Aw $(0,629)$, seguida das amostras F2 $(0,645)$ e F4 $(0,698)$. Referente às amostras que continham combinação de edulcorantes, a que apresentou menor atividade de água foi a formulação F1 $(0,651)$, seguida das formulações F5 $(0,655)$ e F6 $(0,716)$. Tais variações são consequência das diferentes características de higroscopicidade entre os edulcorantes. Os valores de atividade de água encontrados para as seis formulações, entre 0,629 e 0,716, são considerados adequados para evitar o desenvolvimento de microrganismos (BRAGA et al., 2005).

Foram encontrados em $100 \mathrm{~g}$ de biscoito teores de proteínas entre 15,54 e 18,56 g, lipídios entre 24,56 e 25,94 g, fibras alimentares entre 29,78 e 30,08 g e cinzas entre 2,61 e 2,97 g. LOPES et al. (2008) utilizaram 20\% de FSA na elaboração de pão francês, obtendo os seguintes resultados 
em relação a composição química (em g/100 g de pão): proteínas 11,2 \pm 0,1, lipídios 3,8 \pm 0,7, fibras totais 3,0 $\pm 0,0$ e cinzas 2,2 $\pm 0,1$. FINCO et al. (2009) elaboraram biscoitos contendo $10 \%$ de farinha de beringela que apresentaram 7,97\% de proteínas, 8,5\% de lipídios, 14,11\% de fibras e $1,01 \%$ de cinzas. Ambos os estudos apresentaram resultados inferiores aos obtidos no trabalho atual, devido à menor concentração de farinha alternativa adicionada nos dois produtos.

As funções da semente de abóbora são várias. Estudos como de MOHAMED et al. (2009), que avaliaram a ação da farinha da semente através da alimentação de ratos que apresentavam uma toxicidade hepática aguda induzida por tetracloreto de carbono, mostraram que, após quatro semanas de tratamento com a semente, melhoraram as funções das enzimas hepáticas e o perfil lipídico, além do aumento dos níveis das enzimas antioxidantes. Os autores concluíram que a utilização da FSA pode ser útil para pacientes que sofrem de hepatopatias, devido à sua atividade hepatoprotetora e hipolipidemiante. CERQUEIRA et al. (2008a) concluíram em estudo experimental, que a farinha de semente de abóbora interfere no metabolismo diminuindo significativamente os níveis de glicose e triacilgliceróis séricos. Tal ação também foi comprovada por QUANHONG et al. (2003), que avaliaram a melhora da tolerância a glicose em ratos diabéticos tratados com a farinha da semente. Em outro estudo experimental de CERQUEIRA et al. (2008b), os autores relataram que a FSA tem potencial como fonte de fibra e atua aumentando o peso e o volume fecal, promovendo laxação.

Deste modo, a incorporação da FSA em biscoitos torna-se uma alternativa viável de consumo, agregando benefícios nutricionais, de acordo com os estudos citados, e ainda por ser rica em cumarina e curcubitacina, agindo como expectorante e anti-inflamatório, respectivamente (SUZUKI, 2008). Contudo, deve-se ter o cuidado no preparo dessa semente, pois possui fatores antinutricionais, que podem afetar a biodisponibilidade dos seus nutrientes, de acordo com DELVECHIO et al.(2005).

Os altos teores de fibras dos biscoitos de FSA desenvolvidos nesse trabalho são decorrência também da adição da polidextrose. Segundo GOMES et al. (2007), a polidextrose confere textura ao biscoito, além de participar da reação de Maillard, atuando sobre o sabor e a cor do produto, desenvolvendo características semelhantes à sacarose, porém com valor energético reduzido. Esse polímero de glicose apresenta baixo valor calórico, $1 \mathrm{kcal} / \mathrm{g}$, se comparado aos carboidratos, 4 $\mathrm{kcal} / \mathrm{g}$, e ainda seu índice glicêmico é de 5 a 7 , enquanto que o da glicose é 100, sendo indicado para o consumo por diabéticos (RICHTER e LANNES, 2007; PAUCAR-MENACHO et al., 2008). O JECFA não estabeleceu a Ingestão Diária Aceitável (IDA) para a polidextrose e em 1981 esse produto obteve liberação para consumo pela FDA (GOMES et al., 2007). Possui alegação de alimento funcional, desde que a porção do produto sólido forneça no mínimo $3 \mathrm{~g}$ de polidextrose, segundo a Resolução n 18 (BRASIL, 1999), no entanto, este poliol possui tolerância de consumo 
de 90 g/dia por ter efeito laxativo (GOMES et al., 2007; BRASIL, 1998). No estudo atual, no total da formulação foram utilizados $168 \mathrm{~g}$ de polidextrose, portanto cada biscoito possui $1,97 \mathrm{~g}$, assim uma porção de biscoitos ( 3 unidades de $31,65 \mathrm{~g}$ ) apresenta 5,93 g de polidextrose, dessa forma o produto desenvolvido é rico em fibras e pode ser considerado um alimento funcional (BRASIL, 1999).

A Resolução $n^{\circ} 18$ (BRASIL, 1999) preconiza que alimento funcional é aquele que, além das funções básicas nutricionais, produz efeitos metabólicos e fisiológicos benéficos à saúde. Tais alimentos constituem uma das prioridades de pesquisa na área de nutrição e tecnologia, levando-se em conta o interesse do consumidor em alimentos mais saudáveis, que além de nutrir possam modelar o sistema fisiológico do organismo (BORTOLOZO e QUADROS, 2007). As fibras, por exemplo, melhoram a saúde intestinal, reduzem o risco de câncer do cólon e controlam a dislipidemia (JIE et al., 2000; PAUCAR-MENACHO et al., 2008).

\section{Análises sensoriais dos biscoitos}

A Tabela 3 apresenta as médias dos resultados da análise sensorial.

Tabela 3 - Resultados* das análises sensoriais dos biscoitos elaborados com FSA, diferentes edulcorantes e sacarose

\begin{tabular}{|c|c|c|c|c|c|}
\hline Amostra** & Aparência & Sabor & Dureza & Textura & Aceitação \\
\hline$\overline{F 1}$ & $7,80 \pm 0,99^{\mathrm{a}}$ & $5,55 \pm 1,76^{\mathrm{ef}}$ & $6,05 \pm 1,67^{\mathrm{cd}}$ & $6,35 \pm 1,75^{\mathrm{bc}}$ & $6,02 \pm 1,83^{\mathrm{de}}$ \\
\hline $\mathrm{F} 2$ & $7,57 \pm 1,11^{\mathrm{ab}}$ & $5,07 \pm 1,84^{\mathrm{f}}$ & $5,86 \pm 1,75^{\mathrm{d}}$ & $6,18 \pm 1,83^{c}$ & $5,47 \pm 2,02^{\mathrm{e}}$ \\
\hline F3 & $7,63 \pm 1,19^{\mathrm{ab}}$ & $5,83 \pm 1,78^{\mathrm{de}}$ & $7,48 \pm 1,10^{\mathrm{a}}$ & $7,49 \pm 1,26^{\mathrm{a}}$ & $6,53 \pm 1,88^{\mathrm{cd}}$ \\
\hline $\mathrm{F} 4$ & $7,82 \pm 1,14^{\mathrm{a}}$ & $7,27 \pm 1,18^{\mathrm{ab}}$ & $6,57 \pm 1,26^{\mathrm{bc}}$ & $7,27 \pm 1,28^{\mathrm{a}}$ & $7,47 \pm 1,26^{\mathrm{a}}$ \\
\hline F5 & $7,77 \pm 1,15^{\mathrm{a}}$ & $6,42 \pm 1,66^{\mathrm{cd}}$ & $5,98 \pm 1,38^{\mathrm{cd}}$ & $6,89 \pm 1,43^{\mathrm{ab}}$ & $6,80 \pm 1,58^{b c}$ \\
\hline F6 & $7,52 \pm 1,37^{\mathrm{a}}$ & $6,64 \pm 1,60^{\mathrm{bc}}$ & $7,14 \pm 1,18^{\mathrm{ab}}$ & $7,42 \pm 1,17^{\mathrm{a}}$ & $7,18 \pm 1,35^{\mathrm{abc}}$ \\
\hline F7 & $7,19 \pm 1,53^{\mathrm{b}}$ & $7,63 \pm 1,29^{\mathrm{a}}$ & $5,81 \pm 1,71^{\mathrm{d}}$ & $6,98 \pm 1,67^{\mathrm{a}}$ & $7,37 \pm 1,49^{\mathrm{ab}}$ \\
\hline
\end{tabular}

Resultados na mesma coluna com diferentes expoentes diferem significativamente $(p \leq 0,05)$, conforme resultado do teste de Tukey.** F1 - Sucralose + acessulfame-K; F2 - Esteviosídeo; F3 - Acessulfame-K; F4 - Sucralose; F5 Sucralose + esteviosídeo; F6 - Esteviosídeo + acessulfame-K; F7 (padrão) - sacarose.

No atributo aparência a amostra que obteve maior aceitação foi a amostra F4, seguida das amostras F1 e F5. Para o atributo sabor a amostra F7 teve maior aceitação, seguida da amostra F4, já a amostra F2 não apresentou uma boa aceitação, obtendo a menor média de avaliação. Em relação ao atributo aceitação global, a amostra F4 obteve maior média, seguida das F7 e F6, enquanto a F2 apresentou a menor nota na avaliação do atributo aceitação global. De acordo com TORLONI et al. (2007), o esteviosídeo possui sabor residual amargo quando utilizado isoladamente e em função dessa característica deve ser utilizado em associação com outro edulcorante.

O esteviosídeo possui poder dulçor 300 vezes maior que o da sacarose sendo um dos edulcorantes mais populares nos últimos anos (CARDELLO et al., 2000; SRIMAROENG, 2005; CLOS et al., 2008; KAI, 2008; FERNANDES et al., 2009). A quantidade máxima permitida pela 
legislação brasileira para esse edulcorante é de 0,06 g/100 g de alimento (BRASIL, 2008) e a IDA é de $5,5 \mathrm{mg} / \mathrm{kg}$ (CARDELLO et al., 2000). Além de suas propriedades edulcorantes, o esteviosídeo demonstrou ter um potencial terapêutico como contraceptivo e hipotensor, também apresenta efeito anti-hiperglicêmico, hipoglicemiante estimulando a secreção de insulina (SRIMAROENG, 2005; TORLONI et al., 2007). Tornando seguro o seu consumo por pessoas que necessitam de um controle do nível de glicemia, e por ser isento de calorias auxilia no controle de peso (FERREIRA et al., 2009). Todavia, é importante salientar que o uso indiscriminado de edulcorantes pode ter efeitos contrários ao que se espera (VITOLO, 2008).

Embora, as amostras F2 (esteviosídeo) e F3 (acessulfame-K) não tenham apresentado uma boa avaliação sensorial em relação aos atributos sabor e aceitação global, a formulação F6, que continha esteviosídeo e acessulfame-K em combinação, foi a terceira formulação mais aceita. Segundo REIS et al. (2009), os edulcorantes por apresentarem características diferentes, beneficiam o produto quando combinados, e ainda apresentam sinergismo, maximizando assim o sabor e reduzindo o residual amargo. No entanto, algumas combinações apresentam melhor desempenho que outras (MENDONÇA et al., 2005 ), como no caso da amostra F1 que continha a combinação sucralose com acessulfame-K, que não apresentou uma boa avaliação em relação ao atributo aceitação global, enquanto a formulação F4 apenas com sucralose obteve a melhor média no mesmo atributo.

Em relação à textura a amostra F3 teve maior aceitação e também apresentou maior intensidade na dureza, tais resultados provavelmente são consequência das características de higroscopicidade do edulcorante acessulfame-K, uma vez que essa formulação foi a que apresentou menor atividade de água $(0,629)$ (Tabela 2$)$.

O edulcorante acessulfame-K apresenta poder dulçor 200 vezes maior que o da sacarose (TORLONI et al., 2007; NABORS, 2001), sendo seu limite de IDA de 0 a 15 mg/kg (RENWICK, 2006; RICHTER, 2007) e seu limite tecnológico de 0,035 g/100 g de alimento (BRASIL, 2008). Pesquisa sobre o uso do acessulfame-K utilizando estudo citogenético em ratos in vivo, elaborado por MUKHOPADHYAY et al. (2000), mostrou que o consumo desse edulcorante não traz nenhum malefício, desde que utilizada e respeitada a dose da IDA.

Os resultados apresentados na Figura 1 mostram que aproximadamente $45 \%$ dos provadores classificaram a aparência da amostra F1 como "gostei muito", enquanto as formulações F3 e F4 receberam essa mesma avaliação por $40 \%$ dos provadores. 
Figura 1- Distribuição em frequência dos valores da escala atribuídos pelos provadores às amostras de biscoitos 1:1 FSA e FT, e sem adição de açúcar, quanto à intensidade dos atributos A- Aparência, B- Sabor, C- Dureza, D- Textura, E- Aceitação global.

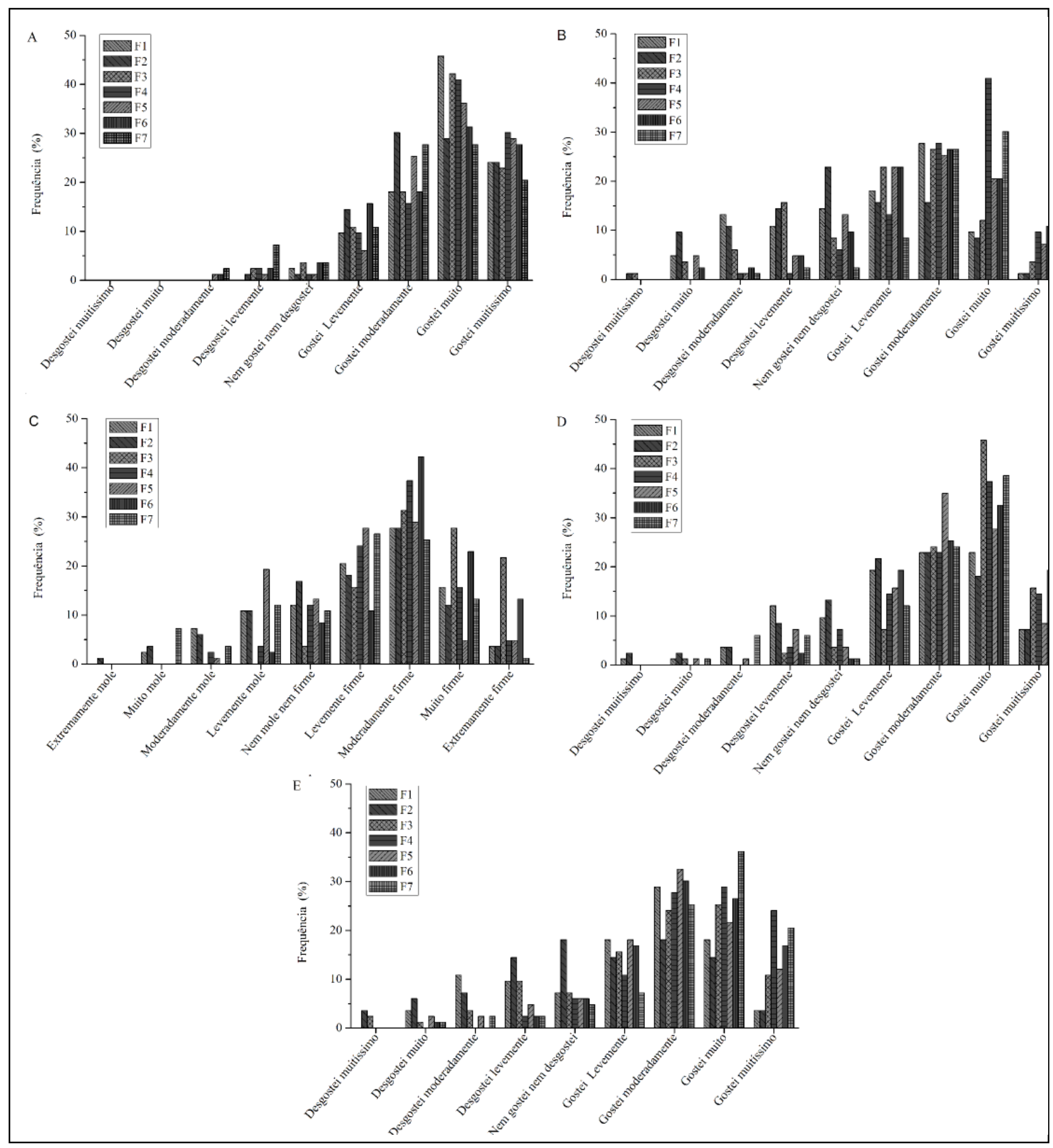

Em relação à intensidade da dureza, em torno de $45 \%$ dos provadores consideraram a amostra F6 como "moderadamente firme". Os sabores das amostras F4 (sucralose) e F7 (sacarose) foram considerados como "gostei muito" por aproximadamente 40 e 30\% dos provadores, respectivamente. Tais resultados indicam uma boa aceitação dos biscoitos dietéticos com o edulcorante sucralose. Isso se deve às semelhanças de características com a sacarose, uma vez que é o único edulcorante derivado do açúcar (FERREIRA et al., 2009). GRANADA et al. (2005) 
utilizaram o edulcorante sucralose no desenvolvimento de geléia com substituição parcial da sacarose. Na avaliação sensorial das formulações elaboradas os provadores não perceberam diferenças de sabor e doçura em comparação com a amostra controle, indicando que a sucralose pode ser utilizada como substituto da sacarose, sem alterar as características organolépticas do produto. REIS et al. (2009) elaboraram iogurtes light com o uso de aspartame, sucralose, acessulfame-K e aspartame/acessulfame-K e compararam as características sensoriais dessas formulações com uma padrão à base de sacarose. Os resultados indicaram que as amostras eram semelhantes, havendo maior preferência pelas formulações com sacarose e sucralose.

A sucralose apresenta um poder de doçura 600 vezes superior ao da sacarose, não possui sabor residual amargo (MENDONÇA et al., 2005; BORTOLOZO, 2007; SCLAFANI e RICHARD, 2004; FERREIRA et al., 2009), sua IDA é de 15 mg/kg (TORLONI et al., 2007) e seu limite tecnológico estabelecido pela legislação brasileira é de 0,04 g/100 g de alimento (BRASIL, 2008). Várias pesquisas mostraram que esse edulcorante não apresenta efeitos tóxicos, carcinogênicos, reprodutivos e neurológicos (TORLONI et al., 2007). Não acrescenta calorias, sendo considerado um edulcorante não nutritivo, podendo ser utilizado por diabéticos, fenilcetonúricos e gestantes (RICHTER e LANNES, 2007; SCLAFANI e RICHARD, 2004).

Os produtos a base de edulcorantes são recomendados para dietas especiais, de emagrecimento ou de restrição (BRASIL, 1998), podendo ser consumidos por pessoas diabéticas, obesas, ou ainda por aquelas que não apresentam nenhuma patologia, contudo, deve-se ter o cuidado de não ultrapassar a IDA (VITOLO, 2008). O produto que tiver substituição da sacarose por um edulcorante de alta intensidade deve ser analisado, garantindo, deste modo, a aplicação do melhor edulcorante e a quantidade adequada para conferir o mesmo sabor doce (BAYARRI et al., 2007).

\section{Conclusão}

Os resultados físico-químicos e sensoriais obtidos demonstraram a viabilidade da adição de semente de abóbora em forma de farinha a fim de obter biscoitos enriquecidos em fibra alimentar, com qualidade nutricional e organoléptica, e ainda da utilização de edulcorantes intensivos, principalmente a sucralose, e do agente de corpo polidextrose na elaboração de biscoitos sem adição de açúcar.

\footnotetext{
Abstract

The search for food sugar free is growing more and more, both by people with diabetes mellitus, and by consumers who seek products with reduced sugar content. Moreover, currently, in order to minimize the amount of agro-industrial residues became important to use these in the development of alternative foods rich in fiber, minerals and fatty acids,
} 
such as pumpkin seed. This work aimed to develop sugar free cookies, using intense sweeteners, polydextrose and pumpkin seed flour, which have sensory and nutritional quality. The sweeteners were: sucralose, acesulfame $\mathrm{K}$ and stevioside, alone and in combination. The pumpkin seed and wheat flours were used in a 1:1 ratio. With the total exclusion of sugar was necessary to use polydextrose, being an ingredient rich in fiber allowing correction of body and prebiotic effect of the product. All samples were subjected to chemical analysis and sensory. The results of the chemical composition highlighted significant levels of fiber, lipids and proteins in all formulations. In sensory analysis, the results showed that the use of sucralose surpassed acceptance among the samples analyzed, even in relation to the standard formulation, which contained sugar. The results demonstrated the feasibility of adding pumpkin seed in the form of flour, order to get biscuits fortified with dietary fiber, with organoleptic quality, and even the use of intense sweeteners and polydextrose in the preparation of biscuits sugar free.

Key-words: Seed; pumpkin; biscuit; sucrose.

\section{Referências}

AMBROSIO, C.L.B.; CAMPOS, F.A.C.S.; FARO, Z.P. Carotenóides como alternativa contra a hipovitaminose A. Revista Nutrição, v. 19, n. 2, p. 233-243, 2006.

AOAC. Association of Official Analytical Chemists. Official Methods of Analysis. 15.ed. Arlington: AOAC, p.1298, 1995.

BAYARRI, S.; IZQUIERDO, L.; COSTELL, E. Sweetening power of aspartame in hydrocolloids gels: Influence of texture. Food Hydrocolloids, v. 21, n. 8, p. 1265-1274, 2007.

BORTOLOZO, E. Q.; QUADROS, R. H. M. Aplicação de inulina e sucralose em iogurte. UTFPR, v. 1, n. 1, p.37-47, 2007.

BRAGA, G. C.; BIAGI, J. D.; SALIBE A. B.; VALENTINI, S. R. T.; VICENTE E. Variações de cor e de atividade de água Agaricus blazei desidratado e armazenado em diferentes embalagens plásticas. Acta Scientiarum Technology., v. 27, n. 1, p. 83-87, 2005.

BRASIL. Ministério da Saúde. Agência Nacional de Vigilância Sanitária. Portaria n 318 de 24 de novembro de 1995. Aprova o uso de Sucralose com a função de edulcorante em alimentos e bebidas dietéticas. Diário Oficial [da República Federativa do Brasil], Brasília, 28 de novembro de 1995.

BRASIL. Ministério da Saúde. Agência Nacional de Vigilância Sanitária. Portaria $\mathrm{n}^{\circ} 29$, de 13 de janeiro de 1998. Regulamento Técnico referente a Alimentos para Fins Especiais. Diário Oficial [da República Federativa do Brasil], Brasília, de 30 de março de 1998.

BRASIL. Ministério da Saúde. Agência Nacional de Vigilância Sanitária. Resolução n ${ }^{\circ} 18$ de 30 de abril de 1999. Regulamento Técnico que estabelece as diretrizes básicas para análise e comprovação de propriedades funcionais e ou de saúde alegadas em rotulagem de alimentos. Diário Oficial [da República Federativa do Brasil], Brasília, 03 de maio de 1999.

BRASIL. Ministério da Saúde. Agência Nacional de Vigilância Sanitária. Resolução RDC no 18 , de 24 de março de 2008. Regulamento Técnico que autoriza o uso de aditivos edulcorantes em alimentos, com seus respectivos limites máximos. Diário Oficial [da República Federativa do Brasil], Brasília, 25 de março de 2008. 
CARDELlO, H. M. A. B.; SILVA, M. A. A. P.; DAMÁSIO, M. H. Análise descritiva quantitativa de edulcorantes em diferentes concentrações. Ciência e Tecnologia de Alimentos, v. 20, n. 3, p. 318-328, 2000.

CARDOSO, J. M. P.; BOLINI, H. M. A Diferent sweeteners in peach nectar: Ideal and equivalent sweetness. Food Research. International, v. 40, n. 10, p. 1249-1253, 2007.

CERQUEIRA, P. M.; FEITAS, M. C. J.; PUMAR, M.; SANTANGELO, S. B. Efeito da farinha de semente de abóbora (Curcubita maxima, L.) sobre o metabolismo glicídico e lipídico em ratos. Revista Nutrição, v. 21, n. 2, p.129-136, 2008a.

CERQUEIRA, P. M.; FEITAS, M. C. J.; PUMAR, M.; SANTANGELO, S. B. Avaliação do efeito fisiológico da farinha de semente de abóbora (Curcubita maxima, L.) no trato intestinal de ratos. Ciência e Tecnologia de Alimentos, v. 28, (supl.), p. 7-13, 2008 b.

CLOS, J. F.; DUBOIS, G. E.; PRAKASH, I. Photostability of rebaudioside A and Stevioside in Beverages. Journal of Agricultural Food Chemistry, v. 56, n. 18, p. 8507-8513, 2008.

DEL-VECHIO, G.; CORRÊA, A. D., ABREU, C. M. P.; SANTOS, C. D. Efeito do tratamento térmico em sementes de abóboras (Curcubita spp.) sobre os níveis de fatores antinutricionais e/ou tóxicos. Ciência e Agrotecnologia., v. 29, n. 2, p. 369-376, 2005.

ESTELLER, M. S. Fabricação de pães com reduzido teor calórico e modificações reológicas ocorridas durante o armazenamento. 2004. 248f. Dissertação (Mestrado em Tecnologia Bioquímico-Farmacêutica), USP, São Paulo, 2004.

FERNANDES, A. G.; SOUSA, P. H. M.; MAIA, G. A.; SILVA, D. S.; SANTOS, S. M. L. Avaliação sensorial de bebidas de goiaba adoçadas com diferentes agentes adoçantes. Ciência e Tecnologia de Alimentos, v. 29, n. 2, p. 358364, 2009.

FERREIRA, V. F.; ROCHA, D. R.; SILVA, F. C. Potencialidades e oportunidades na química da sacarose e outros açúcares. Química Nova, v. 32, n. 3, p. 623-638, 2009.

FINCO, A. M. O.; BEZERRA, J. R. M. V.; RIGO, M.; CÓRDOVA, K. R. V. Elaboração de biscoitos com adição de farinha de beringela. Revista Brasileira de Tecnologia Agroindustrial, v. 3, n. 1, p. 49-59, 2009.

GOMES, C. R.; VISSOTTO, F. Z.; FADINI, A. L; FARIA, E. V.; LUIZ, A. M. Influência de diferentes agentes de corpo nas características reológicas e sensoriais de chocolates diet em sacarose e light em calorias. Ciência e Tecnologia de Alimentos, v. 27, n. 3, p. 787-792, 2007.

GRANADA; G. G.; ZAMBIAZI, R. C.; MENDONÇA; C. R. B.; SILVA, E. Caracterização física, química, microbiológica e sensorial de geléias light de abacaxi. Ciência e Tecnologia de Alimentos, v. 25, n. 4, p. 629-635, 2005.

INSTITUTO ADOLFO LUTZ. Normas analíticas do Instituto Adolfo Lutz: métodos químicos e físicos para análise de alimentos. 4 ed. São Paulo: Instituto Adolfo Lutz, 2005.

JIE, Z.; BANG-YAO, L.; MING-JIE, X.; HAI-WEI, L.; ZU-KANG, K.; TING-SONG, W.; CRAIG S. A. Studies on the effects of polydextrose intake on physiologic functions in Chinese people. American Journal of Clinical Nutrition, v. 72, n. 6, p. 1503-1509, 2000.

KAI, M. K. Steviol glycosides as intense sweeteners. Food Standards, v.13, n.8, p.1-100, 2008.

LOPES, M. V.; BENEVIDES, J. M. C.; LIMA, J. F. O.; OLIVEIRA, L. C.; SILVA, J. S. J.; RODRIGUES, J. R. M. Uso de farinha mista de trigo e semente de abóbora (Curcubita spp.) na elaboração de pão francês. Higiene Alimentar, v. 22, n.163, p. 88-93, 2008.

MACEDO, C.D. Desenvolvendo competências e habilidades no curso técnico de nutrição e dietética do CEFETUberaba, MG: Formulações de produtos com substituição de sacarose para indivíduos diabéticos. $78 \mathrm{f}$. Dissertação (Mestrado em Educação Agrícola). UFRRJ, São Paulo, 2005. 
MENDONÇA, R. B. C.; ZAMBIAZI, C. R; GULARTE, A. M.; GRANADA, G. G. Características sensoriais de compotas de pêssego light elaboradas com sucralose e acessulfame-K. Ciência e Tecnologia de Alimentos,.v. 25, n. 3, p. 401-407, 2005.

MOHAMED, A. R.; RAMADAN, R. S.; AHMED, L. A. Effect of substituting pumpkin seed protein isolate for casein on serum liver enzymes, lipid profile and antioxidant enzymes in $\mathrm{CCl}_{4}$-intoxicated rats. Advances Biological Resourches, v. 3, n. 1-2, p. 9-15, 2009.

MUKHOPADHYAY, M.; MUKHERJEE, A.; CHAKRABARTI, J. In vivo cytogenetic studies on blends of aspartame and acesulfame-K. Food and Chemical Toxicology, v. 38, n. 1, p. 75-77, 2000.

NABORS, L. O. B. Alternative Sweeteners. 3.ed., New York., 2001.

PAUCAR-MENACHO, L. M.; SILVA, L. H.; BARRETTO, P. A. A.; MAZAL, G.; FAKHOURI, F. M.; STEEL, C. J.; COLLARES-QUEIROZ' F. P. Desenvolvimento de massa alimentícia fresca funcional com a adição de isolado protéico de soja e polidextrose utilizando páprica como corante. Ciência e Tecnologia de Alimentos, v. 28, n. 4, p. 767-778, 2008.

QUANHONG, L. et al. (sic) Study on the hypoglycemic action of pumpkin extract in diabet rat. Acta Nutrimenta Sinica, v.25, n.1, p.34-36, 2003.

REIS, R. C.; MINIM, V. P. R.; DIAS, B. R. P.; CHAVEs, J. B. P.; MINIM, L. A. Impacto da utilização de diferentes edulcorantes na eceitabilidade de iogurte light sabor morango. Revista Alimentos e Nutrição, v. 20, n. 1, p. 53-60, 2009.

RENWICK, A.G. The intake of intense sweeteners - an update review. Food Additives and Contaminnats,v. 23, n. 4, p. 327-338, 2006.

RICHTER, M.; LANNES, C.S.S. Ingredientes usados na indústria de chocolates. Revista Brasileira de Ciências Farmecêuticas, v. 43, n. 3, p. 357-369, 2007.

SCLAFANI, A.; RICHARD, A.C. Female rats show a bimodal preference response to the artificial sweetener sucralose. Chemical Senses, v. 29, n. 6, p. 523-528, 2004.

SRIMAROENG, C.; CHATSUDTHIPONG, V.; ASLAMKHAN, G. A.; PRITCHARD, J. B. Transport of the natural sweetener stevioside and its aglycone steviol by human organic anion transporter (hOAT1; SLC22A6) and hOAT3 (SLC22A8). Journal of Pharmacological Experimental Therapeutics, v. 31, n. 32,p. 621-628, 2005.

SUZUKI, E. Efeito das fibras alimentares de abóbora na inflamação intestinal induzida em ratos. 2008. 74f. Dissertação (Mestrado em Farmacologia). UNICAMP, Campinas, 2008.

TORLONI, M. R.; NAKAMURA, M. U.; MEGALE, A. O uso de adoçantes na gravidez: uma análise dos produtos disponíveis no Brasil. Revista Brasileira de Ginecologia e Obstetrícia, v. 29, n. 5, p. 267-75, 2007.

VITOLO, M.R. Nutrição: da gestação ao envelhecimento. Rio de Janeiro: Rubio, 2008.

\section{Dados dos autores:}

Nome completo: Juliana Bergonsi da Silva

Filiação institucional: Centro Universitário - UNIVATES

Departamento: CCBS

Função ou cargo ocupado: Graduanda do curso de Nutrição

Endereço: Rua Pedro Albino Muller, 428, ap. 802. Bairro Florestal. Lajeado. RS. Brasil. CEP: 95900-000

Telefones para contato: (51) 91778356, (51) 96855846

e-mail:julianabergonsi@gmail.com 
Nome completo: Claucia Fernanda Volken de Souza

Filiação institucional: Centro Universitário - UNIVATES

Departamento: CETEC

Função ou cargo ocupado: Professora adjunta

Endereço: Rua Senador Salgado Filho, 257/404. Centro. Esteio. RS. Brasil. CEP 93260-140.

Telefones para contato: (51)99490016, (51)34592469

e-mail: clauciavolken@ig.com.brou clauciavolken@bol.com.br

Nome completo: Cláudia Schlabitz

Filiação institucional: Centro Universitário - UNIVATES

Departamento: CETEC

Função: laboratorista

Endereço: Rua Pedro Theobaldo Breitenbach, 3434 - CPC 20. Conventos. Lajeado. RS. Brasil. CEP 95900-000.

Telefone para contato: (51) 37489511

e-mail: claudinhakimica@yahoo.com.br 